\title{
O mundo segundo os quilombolas do bairro alto (Ilha de Marajó): Cosmovisões acerca da vida e das relações sociedade e natureza
}

\author{
Maíra Fernanda Tavares de Melo \\ Mestranda do PPGA \\ Universidade Federal do Pará \\ Flávio Bezerra Barros \\ Professor do PPGA \\ Universidade Federal do Pará
}

Resumo: Na Amazônia, os povos da floresta possuem representações próprias da vida, do mundo e do lugar dos humanos e não humanos neste mundo. Este artigo tem como objetivo descrever os saberes e as práticas relacionadas às cosmovisões em uma comunidade quilombola da Ilha do Marajó, Pará. Utilizamo-nos do método etnográfico e da observação participante para discutir os elementos da pesquisa, dialogando com autores como Viveiros de Castro (1986; 1996; 2006), Bruno Latour (1994); Marcel Mauss, (2003), Lévi-Strauss (2005).

Palavras-chave: cosmologia; povos e comunidades tradicionais; natureza e cultura; Amazônia. 


\title{
The World according to the quilombolas of the Bairro Alto (Marajó Island): Cosmovisions on life and society- nature relationships
}

\begin{abstract}
In the Amazon, traditional peoples have their own representations of life, the world and the place of humans and nonhumans in this world. This article aims to describe the knowledge and practices related to cosmovisions in a quilombola community on the Marajó Island, Pará. We use the ethnographic method and the participant observation to discuss the elements of the research, dialoguing the results, as well as the authors as Viveiros de Castro (1986, 1996, 2006), Bruno Latour (1994); Marcel Mauss (2003); Lévi-Strauss (2005).
\end{abstract}

Keywords: cosmology; traditional peoples and communities; nature and culture; Amazon.

\section{El Mundo de acuerdo con el Pueblo quilombola (Isla de Marajó): Visiones de la vida y de las relaciones con la sociedade y naturaleza}

Resúmen: En la amazonia, los pueblos forestales tienen sus propias representaciones de la vida, el mundo, el lugar de los humanos e no humanos en este mundo. Este artículo tiene como objetivo describir los conocimientos y practicas relacionadas con visiones del mundo en una comunidad del quilombo de la isla de Marajó, Pará. Se utilizo el método etnográfico y la observación para obtener los resultados, así como estos autores Viveiros de Castro (1986, 1996, 2006), Bruno Latour (1994), Marcel Mauss, (2003), Lévi-Strauss (2005).

Palabras clave: cosmología; los pueblos y comunidades tradicionales; naturaleza y cultura, Amazonas. 


\section{Contextos iniciais}

Muito mais do que representar a grande riqueza biológica comprovável a dados estatísticos, a Amazônia é palco de imensurável diversidade cultural. A grande sociobiodiversidade existente nesse pedaço do Brasil nos convida a pensar nas relações existentes entre o meio ambiente, os seres humanos e não humanos. E em como cada um desses elementos se constrói e reafirma seu espaço nas realidades locais e nas cosmologias da floresta. Nesse sentido, os povos indígenas e tradicionais que nela encontram morada, possuem formas de interpretar o mundo e de compreender as relações possíveis com os seres que a habitam de maneiras específicas e seguindo ordenações de suas próprias culturas.

Os povos quilombolas trazem ainda particularidades que remetem a todo o histórico de luta e resistência ao sistema escravista que ocorreu no Brasil entre os séculos XVII e XIX. O território das comunidades guarda histórias sobre o tempo em que o lugar era, sobretudo, um acampamento guerreiro, como o significado do próprio nome nos aponta, elemento que se tornou, decerto, parte da construção cosmológica dessas populações. A comunidade quilombola do Bairro Alto, Ilha do Marajó (Pará), lócus em que conduzimos nossas pesquisas, não fica fora desse contexto, por também apresentar tais elementos.

Lévi-Strauss (2005) nos diz que essas formas de ordenação e compreensão do mundo são inerentes aos seres e por isso, toda e qualquer sociedade o fará, segundo os elementos que lhe são mais caros, segundo aquilo que dão mais importância e possui maior significado. E é por isso que encontramos tamanha diversidade na forma como o mundo e a natureza são interpretados quando estudamos cultura.

Nessa perspectiva, Latour (1994) diz que a dificuldade de entendimento das culturas reside no fato de ou querermos excluir a natureza das análises ou incluí-la sob a forma de uma natureza universal, mas que na verdade é universal somente para nós - os ocidentais, treinados na ciência moderna. E por isso propõe que "não existem nem culturas - diferentes ou universais - nem uma natureza universal. Existem apenas naturezas-culturas, as quais constituem a única base possível para comparações" (LATOUR, 1994: 102). Dessa forma, o autor quer dizer que enquanto não enxergarmos que cada sociedade em si mesma possui cultura e natureza próprias vamos acabar analisando-as de forma reducionista ou sob o ponto de vista de uma ciência universal que não contempla os signos e significados de uma cultura específica.

Ademais, não podemos deixar de comentar que:

A clássica divisória natureza (multinaturalismo) versus cultura (monoculturalismo) não deve ser utilizada para descrever domínios internos das cosmologias não ocidentais, pois tais categorias não possuem o mesmo conteúdo, nem o mesmo estatuto de seus análogos ocidentais". (TEIXEIRA, 2006: 122)

Analisando a comunidade de Bairro Alto, partimos, pois, destes dois princípios: Que ela possua sua própria natureza-cultura e que suas cosmologias não devem ser comparadas ou utilizadas na compreensão de comunidades outras, pois são construções originais formuladas pelos próprios agentes sociais. 
Sobre as diversas cosmologias que compõem o cenário amazônico, muito se tem pesquisado sob o olhar da perspectiva indígena (Descola, 2004; Erikson, 2000; Garcia, 2010; 2012a; 2012b; Lima, 2008; Mazza, 2009; Posey e Elisabetsky, 1991; Silva, 2002; Stolze-Lima, 1996; Veiga, 2000; Viveiros de Castro, 1986; 1996; 2006). Os trabalhos analisam as sociedades indígenas em diversas frentes, mas principalmente, enfocam questões de caça e território, relações animal-espírito-pessoa e as cosmovisões de suas respectivas sociedades. No entanto, estudos relacionados aos povos não indígenas que vivem no contexto amazônico, têm sido, de certa forma, menos contemplados. Os principais trabalhos tratam sobre a categoria "ribeirinhos" e "caboclos amazônicos", tendo em Valentin Wawzyniak (2003; 2008, 2012) e Maués (1990, 1995, 1999, 2005) os seus principais pesquisadores. Depois deles, parcos textos abordam a temática de forma central, e quando o fazem, inserem-no como parte integrante de outro assunto.

Em se tratando de comunidades quilombolas, vemos mais ainda esta invisibilidade. As temáticas ligadas a elas centram-se em aspectos outros como etnicidade, identidade, memória social e organização política; pouco se fala das cosmologias locais. Diante de tantas peculiaridades observadas em campo, interessou-nos conhecer e compreender os elementos que formam a cosmologia da comunidade quilombola do Bairro Alto, a fim de perceber como esta se integra às práticas produtivas e ao conhecimento tradicional.

\section{Dos caminhos que levam ao Bairro Alto}

Como dissemos, a pesquisa foi desenvolvida na comunidade quilombola de Bairro Alto, entre os meses de janeiro a outubro de 2016, utilizando técnicas de etnografia (CLIFFORD, 1998) e de observação participante (MALINOWSKI, 1976), com o objetivo de descrever a cosmologia local a partir das práticas e saberes dos interlocutores. Os trechos de entrevistas aqui transcritas possuem identificação fictícia, por entendermos que a identidade dos interlocutores deve ser preservada.

A comunidade está situada no Arquipélago do Marajó, localizado a oo $45^{\prime} 12^{\prime} \mathrm{S} / 48^{\circ} 31^{\prime}$ 'oo"W na zona rural do município de Salvaterra, no Estado do Pará (Figura 1).

A região pode ser acessada pelos ares, no entanto são pelas águas da Baía do Marajó que a maior parte da população residente na Ilha e seus visitantes se locomovem mais frequentemente. São aproximadamente 3 a 4 horas de viagem (90 km de distância) desde o embarque em Belém, capital do Estado, à chegada ao porto Camará, a porta de entrada às várias cidades da microrregião do Arari . Chegando ao porto, ainda é necessário continuar a viagem por terra. Por isso, vans e ônibus oferecem o serviço desse pequeno trajeto de pouco mais de $20 \mathrm{~km}$ até o centro urbano de Salvaterra. Ao final deste pequeno trajeto chega-se, de fato, à cidade. A comunidade de Bairro Alto, como dissemos, se localiza na zona rural e assim, descendo de nosso segundo transporte ainda temos de percorrer $12 \mathrm{~km}$ até o quilombo. Esse percurso pode ser feito por moto táxis, taxis, ônibus ou até mesmo de bicicleta, por caminhos alternativos e mais curtos, como pudemos perceber em nossa primeira viagem de campo. Os residentes da

\footnotetext{
${ }^{1}$ A ilha do Marajó, considerada a maior ilha fluviomarítima do mundo, possui dezesseis municípios, divididos politicamente em três microrregiões: O Arari, Portel e Furo de Breves. O município de Salvaterra pertence à microrregião do Arari e localiza-se geograficamente na região nordeste da ilha. (BRASIL, 2007).
} 
comunidade, normalmente, utilizam-se desses caminhos alternativos tanto para fugir do asfalto e do calor por ele provocado, como também para reduzir distâncias e seguir por caminhos ensinados por seus antepassados e guardados até hoje na memória.

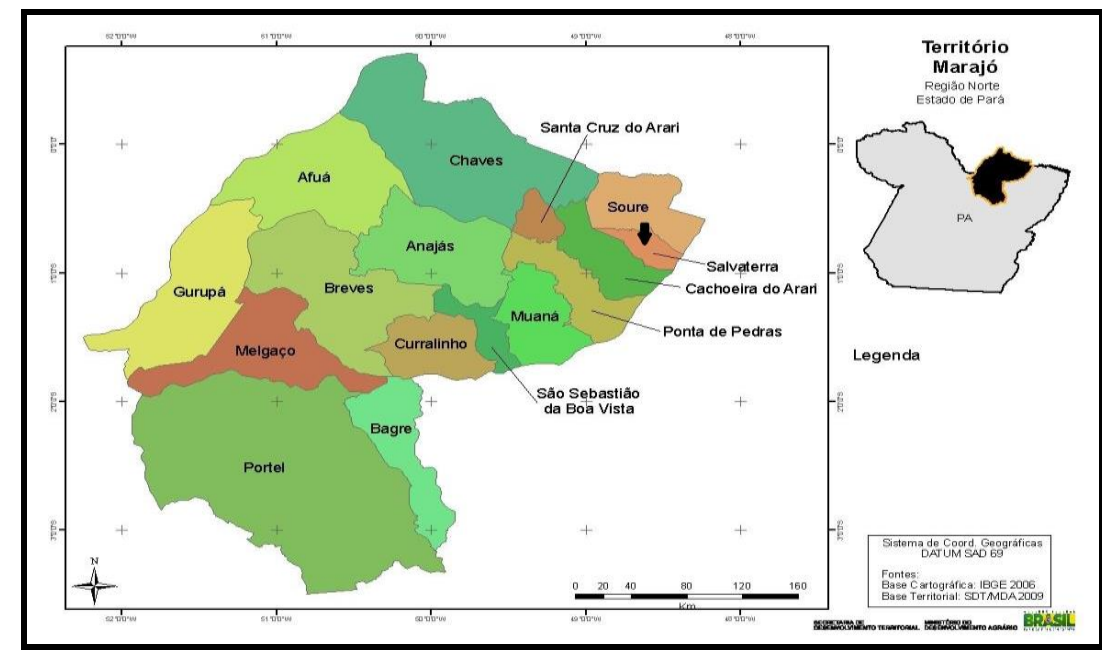

Figura 1: Localização geográfica do município de Salvaterra, modificado pela autora. Fonte: MDA/SDT (2009).

Tendo em vista sua extensão territorial (1.039.072 km2) e o número de habitantes (pouco mais de 20.000), Salvaterra é o município da Ilha do Marajó que mais concentra comunidades quilombolas no Pará. De acordo com MALUNGU (2006) até o referido ano doze comunidades haviam sido identificadas. Atualmente esse número aumentou para dezesseis comunidades (FCP, 2016), com reais possibilidades de crescimento, haja vista a maior articulação política da população. No caso de Bairro Alto, o processo de titulação foi iniciado, mas ainda não obteve resposta definitiva dos órgãos competentes. A comunidade é reconhecida pela Fundação Cultural Palmares, que não tem poder de titulação, apenas de reconhecer e certificar as comunidades.

De acordo com a presidente da Associação dos Remanescentes de Quilombos do Bairro Alto (ARQBA), Alana Maciel, moram atualmente na comunidade 130 famílias, aproximadamente 350 pessoas, que sobrevivem, principalmente, da pesca, da caça e do extrativismo vegetal em períodos sazonais (Figura 2). O açaí (Euterpe oleracea), o bacuri (Platonia insignis) e a mandioca (Manihot esculenta crantz) são os principais produtos vegetais que se encontram no sistema de produção e de autossustento. O cotidiano do Bairro Alto gira em torno do modo de vida tradicional, em que as atividades mais fortemente desenvolvidas estão diretamente ligadas à natureza. E são a partir dessas relações com o ambiente natural que percebemos de forma mais aguda as construções cosmológicas locais. É em contato com o rio e suas ramificações, bem como com a mata, que os sujeitos revelam suas práticas e visões de mundo, construídas a partir de um sistema de crenças próprio. 
Durante a pesquisa de campo, pudemos perceber a inegável aproximação da natureza na construção do sistema de crenças e nas formas de interpretar o mundo que os cerca e é sobre isso que iremos nos deter agora.

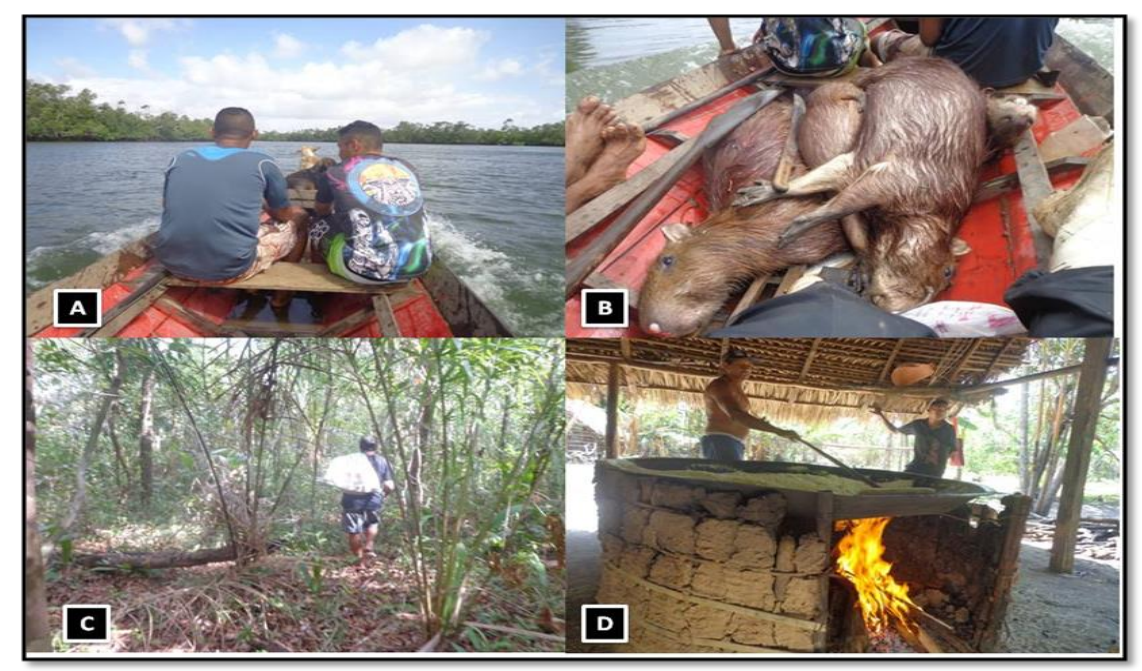

Figura 2: As principais atividades produtivas no Bairro Alto. A- Pesca; B- Caça; C- Coleta de Bacuri e D - Confecção de Farinha. Foto: Maíra Melo. Janeiro/2016.

\section{A diversidade dos mundos}

Olha, eu não sei, mas devido a minha convivência, eu fico imaginando que nós temos três mundos... Pra mim, nós temos três mundos... Que é o mundo espiritual, esse nosso que nós vivemos aqui e o mundo dos encantados. O mundo espiritual é o dos espíritos, dos que já morreram... Esse aqui é o nosso... E tem o deles, lá no fundo [apontando para o rio]... D. C, 76 .

A partir do relato de D. C, assim como nas diversas conversas que presenciamos ou nas infinitas práticas que percebemos no cotidiano da comunidade, notamos a construção de três mundos habitados por diferentes seres do universo, mundos esses que se entrecruzam pelo poder de mobilidade de seus habitantes. Cada um deles ocupa um espaço distinto na tradição cosmológica local. O céu, a terra e a água e as matas são os níveis físicos em que esses mundos podem ser acessados - a quem tiver permissão.

O primeiro deles é o mundo dos espíritos, que fica acima de nós, no céu, e é o lugar para onde vão os espíritos dos seres que já partiram da terra. Em outras palavras, é o lugar em que vivem os espíritos dos mortos que alcançaram a paz e não perambulam sem rumo como andarilhos pelos caminhos da terra. Válido, pois, é ressaltar que este mundo é invisível e impossível de ser acessado por aqueles que possuem vida e não possuem o dom de fazer o intermédio entre os mundos, dom exclusivamente pertencente aos pajés.

O segundo é o mundo dos vivos, localizado no espaço em que os humanos possuem morada. Está no meio. É o mundo no qual nos encontramos e o mundo onde as interconexões com os demais mundos são possíveis de acontecer. O mundo dos vivos é o mundo físico, visível e palpável, onde os outros mundos exercem poder de intervenção. Morada, não somente, de humanos, mas 
também de não humanos que ou ainda não encontraram seus caminhos - as visagens - ou possuem tarefas a desempenhar na terra - os encantados - como, por exemplo, a proteção do meio ambiente.

O terceiro mundo, localizado nas profundezas das águas ou das matas, é o chamado mundo encantado, no qual as criaturas "encantadas" habitam. Segundo os interlocutores, são os seres deste mundo que têm importante papel na proteção dos ambientes naturais, como as matas, os rios, as cabeceiras de igarapé, os campos, etc. Bem como possuem grande influência na vitalidade dos animais, podendo, muitas das vezes, lhes possuírem a fim de se materializarem no mundo dos humanos para assumirem mais fortemente a função de guardiões.

Essa cosmovisão de que o universo divide-se em três mundos e é habitado por seres de natureza humana e não humana, não é exclusiva da naturezacultura da sociedade analisada. Segundo Harris (2004) apud Albuquerque e Faro (2012: 62) a encantaria na Amazônia possui essa característica tridimensional ou múltipla, que faz com que a presença dos encantados nas diversas narrativas locais não seja incomum.

$\mathrm{Na}$ leitura de trabalhos como os de Maués (1990; 2005), podemos entender que o fenômeno da encantaria é, sobretudo, produto das práticas de pajelança entre os povos amazônicos e que este não se prende a heranças de povos específicos, mas forma-se a partir de um agregamento, em diferentes graus, da religiosidade, dos símbolos e significados indígenas, afro-brasileiros e católicos; fazendo dos encantados elementos centrais nas cosmologias amazônicas por misturarem tais elementos.

Por representar tamanha centralidade no assunto que nos propomos a discorrer, deter-nos-emos a partir de agora, a definir mais precisamente o que são encantados e como atuam e influenciam o mundo dos humanos.

Logo que chegamos a campo, ao nos aventurarmos nos questionamentos, relacionados às cosmologias nativas, uma senhora nos disse que na natureza "tudo tem mãe" e que "toda cabeceira tem um dono". No entendimento local, os encantados são essas mães e esses donos ou protetores dos lugares mais puros do mundo, aonde a intervenção humana ainda não chegou. São criaturas tão puras, que não gostam de barulho, muito menos do desrespeito ao ambiente natural, pois fazem desses lugares suas moradas. Por isso são considerados donos dos lugares.

Segundo Maués (2005: 262), os encantados "são seres humanos que não morreram, mas que se encantaram" e que depois de encantados nunca mais voltarão ao mundo dos humanos, permanecendo para sempre no "fundo", o que contrapõe a ideia difundida na comunidade de Bairro Alto em que estes seriam seres em uma categoria à parte; nem vivos e nem mortos, nem humanos e nem animais. Teixeira (2006: 123) também se opõe à visão de encantado discutido por Maués na região do Salgado Paraense, afirmando que: 
O encantado pode ser muita coisa, pode ser um lugar, um animal, pode estar no fundo, na mata e pode não estar, nem ser nada específico. O encantado é um continuum de linguagem, história, valores e de ser; ele está em toda parte e é algo incluído no cotidiano da comunidade”. (Teixeira, 2006: 123)

Esse contexto nos dá margem para mais uma vez reafirmar a noção de naturezas-culturas propostas por Latour (1994), já que, apesar das aproximações não só linguísticas, mas em alguns outros pontos da construção cosmológica, não podemos retirar de nossas vistas que para cada cultura existe uma natureza própria e que torna única as construções coletivas de cada grupo social.

Em relatos colhidos durante a pesquisa de campo, fica muito claro o papel dos encantados: São guardiões e protetores das matas, dos rios, das cabeceiras e afins, que em geral não causam mal algum aos habitantes do mundo vivo. Possuem também função nos trabalhos de pajelança, no entanto podem "malinar" bastante e até matar aqueles que deixarem de respeitar a natureza, cometendo abusos, como podemos avaliar a seguir:

Uma vez ia passando um senhor de lá pra cá na ponte ... que era a primeira ponte ainda. E ele ficou em cima da ponte. Ele ficou caído em cima da ponte... ele não pôde mais andar. Ele passou lá falando nome, falando palavrão... ficou lá. Aí, carregaram ele e levaram ele pra casa de um senhor que era pajé... e ai foi que ele fez o trabalho... Quando ele voltou já foi andando...

\begin{abstract}
Meu marido viajava muito pra fazenda com o tio dele, aí junto com eles foi um rapaz. Esse rapaz ia cantando as cantigas do pajé, né! Ia cantando, fazendo muito barulho... Quando chegaram lá na casa que eles tinham que ficar... Ele chegou com uma dor nele... bem aqui assim... [apontando para o abdômen] Ele rolava no chão... aí trouxeram ele, chegou gritando aqui em casa... aí o pajé fez o trabalho... era uma flechada...

...Tem um dizer... eles não sabiam se era feminino ou masculino né... então a gente tinha que dizer assim: - Meu avô ou minha avó, dê licença de passar pra cá... por aqui não me faça mal! Pra poder passar e se não pedisse, adoecia...” D.C, 76 anos.
\end{abstract}

A partir dos depoimentos de D.C, podemos perceber alguns elementos: O primeiro deles é a agência que esses seres têm perante os humanos, ou seja, o grande poder de interferência que esses seres possuem como vemos nos dois primeiros relatos, em que os encantados "malinaram" com os dois personagens da história, por estes não obedecerem a uma regra implícita e pré-estabelecida de respeito para com eles e para com a natureza.

Outro ponto importante é o papel do pajé como figura intermediária entre o mundo dos humanos e o mundo dos encantados e o único que tem a capacidade de curar males causados por estas criaturas, já que de acordo com nossas observações são os indivíduos que podem conversar com essas criaturas e, de certa forma, influenciá-los a não mais castigar ou retirar o castigo.

$\mathrm{E}$ por fim, podemos perceber ainda, o respeito e a influência desempenhada por eles, o que acaba por modular o modo pelo qual agem os indivíduos da comunidade, como fica evidenciado no terceiro relato. Pedir licença ou desviar dos caminhos que possuem donos são formas de buscar harmonia com os seres do universo e de viver bem na comunidade. 


\section{Os encantados, visagens e outros seres}

O convívio na comunidade nos fez perceber a existência de uma diversidade de seres encantados, como também a coexistência de seres não pertencentes a esta categoria, mas que estão presentes no contexto local e que merecem destaque por também fazerem parte do universo cosmológico marajoara local.

Entre os encantados, existem aqueles que são habitantes das águas, e configuram-se como maioria, dada a natureza aquática do mundo deles, e aqueles habitantes das matas, que na verdade personificam-se apenas em uma entidade, a mãe da mata ou curupira. Caracterizamos a seguir os encantados marcadamente mais destacados.

Como já mencionado, o Curupira, também chamado de mãe do mato, é a criatura responsável por guardar as matas e os seres que nela vivem, sejam animais ou não. Parece estar no limiar entre a humanidade e a animalidade, pois apresenta características das duas naturezas em seu corpo físico.

Já ao tratarmos dos encantados sob o domínio das águas, temos uma maior diversidade. De modo geral, são entidades que protegem pontos específicos da comunidade, como a cabeceira de um rio, um porto em que se atracam canoas ou lagos e igarapés procurados para atividades de pesca. A Sapa da Tororomba, o Jacaré do Portinho, a Cobra do Mucunã e o Lago do Guajará são exemplos desses encantados.

A Sapa da Tororomba é o encantado que guarda a cabeceira do rio Matupirituba, que corta a comunidade longitudinalmente e localiza-se em posição central, por onde todos passam para se deslocar entre os sítios que a formam. Existe uma ponte construída por cima do rio (Figura 3) e que é fonte de vários relatos sobre a existência e ação da "sapa que mora na Tororomba". De acordo com os relatos, a Sapa - que foi vista por uma pajé residente na comunidade - cuida e protege o lugar e por isso tem o poder de "malinar" aqueles que não a respeitem. Além disso, ainda nos foi dito que o nome dado Tororomba - é resultado do som que a água fazia quando vinha das matas e caía na região que se localizava a cabeceira do rio. Ou seja, trata-se da onomatopeia desse barulho. Como podemos ver:

\footnotetext{
... a denominação Tororomba foi porque a cabeceira de lá era bem funda né... um buraco e toda a água que vinha do mato caía lá e fazia um barulho... um estrondo... dava aquele estrondo que se ouvia longe... e aí o morador deu o nome ao estrondo de tororomba... porque o barulho parecia...

...Aí veio uma senhora... e ela era pajé e ela viu... aí era uma sapa... a dona de lá era uma sapa... uma jia grande... Ela viu direitinho ela pular... E a sapa de lá muda de cor, a dona de lá mudava de cor... uma hora tava duma cor, outra hora de outra... assim que ela se apresentava... D.C, 76 anos.
}

Além da Sapa da Tororomba, a Cobra do Igarapé Mucunã é bastante comentada. Segundo os moradores, este encantado seria tão grande, que seu corpo já teria sido visto em regiões afastadas da comunidade. Ela tomba barcos e puxa para "o fundo" aqueles que não respeitam seu espaço, além de estabelecer um limite de canoas que podem pescar no local, como fica evidenciado: 
Ali no Mucunã até duas canoas pode pescar lá... Passou de três canoas, ficou na anarquia lá... Tu larga linha, rede, tudo... Aquela cobra... se fazer zuada ela derruba mermo... sai derrubando o mangal. A.J, 30 anos.

Da mesma forma acontece com o Jacaré do Portinho, que exerceria o mesmo papel, no entanto em outro lugar. Já o Lago do Guajará, também muito conhecido, principalmente pelos pescadores, por ser dotado de grande diversidade de peixes, não tem alguma criatura que o protege, ele em si é encantado, possuindo em sua beira uma região onde se "ouve música, canto de galo, choro de criança, baque de tambor... tudo perto do lago... só que eles [os pescadores] não vê nada... só ouve. Por isso que eles dizem que ele é encantado”, o que nos remete ao que concluiu Teixeira (2006) na região do rio Erepecuru no Amazonas, ao afirmar que o encantado pode ser representado de diversas maneiras, entre elas animais e lugares.

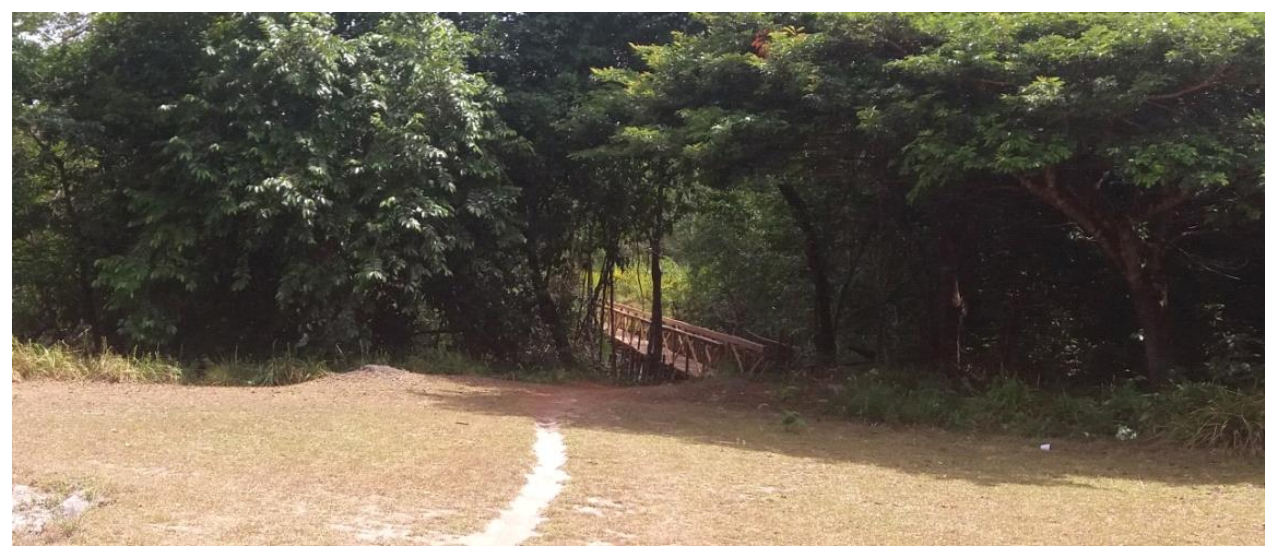

Figura 3: Ponte da Tororomba. Foto: Maíra Melo. Agosto/2016.

Ademais, ainda ouvimos relatos de encantados reconhecidamente presentes no cenário amazônico, como o Boto e a Uiara ou Oraia. O Boto já é personagem conhecido, não só pelos povos tradicionais que vivem em lugares próximos de rios, como pela população amazônica em geral. É o encantado que possui a capacidade de se transformar em humano e seduzir mulheres jovens e belas da comunidade em noites de festa. É muito elegante e usa um chapéu, que esconde o furo característico que o animal possui. Em Bairro Alto, as pessoas dizem que as mulheres são as que mais devem tomar cuidado com ele, principalmente se estiverem "doentes" (menstruadas), evitando a todo custo a beira do rio, já que o encantado teria a capacidade de sentir o odor emitido por estas e puxá-las para dentro do rio, causando, primeiramente, o desaparecimento e, posteriormente, a gravidez dessa mulher.

Já a Uiara é a mãe das águas, e por isso a protetora do mundo dos encantados, que tem a capacidade de visitar as pessoas em seus sonhos e leválas ao fundo dos rios. Quando a pessoa que está sob o seu "encante", chega à sua morada - no fundo do rio - é oferecida a ela uma infinidade de comidas e bebidas, e esta, por sua vez, não deve aceitar sob pena de ficar presa no mundo dos encantados e nunca mais voltar à superfície.

Na pesquisa de Leão (2015), realizada no município de Breves, também na Ilha do Marajó, encontramos um relato muito semelhante ao encontrado na comunidade de Bairro Alto sobre o encantamento da mãe das águas. A autora não identifica o encantado, no entanto, a partir do relato podemos perceber que 
pode se tratar de encantado de semelhante poder ou até mesmo se tratar da mesma entidade.

Independente da relação que possa existir, o fato é que a gama de criaturas não humanas existente na comunidade de Bairro Alto não se limita aos encantados. Outros seres que não pertencem a esse mundo rondam o universo quilombola, entre os quais estão as visagens ou misuras - entidades pertencentes ao mundo dos espíritos - e a Matinta Perera, que parece não ter lugar definido por possuir, segundo os moradores, uma natureza conflitante ou dialógica.

As visagens ou misuras surgem nesse contexto, como espíritos errantes, que andam não só pela mata, mas pelos arredores da comunidade. A partir dos depoimentos, percebemos que estes seres não possuem funções no "nosso mundo" como os encantados, no entanto, recai sobre eles grande temor. A maioria da população relata que "não se deve mexer com as visagens", que se devem evitar caminhos "visagentos" e que a oração é muito importante para deixá-las afastadas de nós, pois elas, de alguma forma, podem interferir na vida humana caso haja desrespeito. Podemos perceber esses aspectos no relato a seguir:

\begin{abstract}
Tem até um bacurizeiro ${ }^{2}$ lá que chamam de bacuri da forquilha... Tava escuro e aquele negócio gemendo lá pra cima né...Quando eu fui chegando perto... diabo! Aquilo foi arrupiando o meu cabelo, ai eu pensei - esse negócio não é boa coisa... Ai ficou gemendo aquilo... vinha gemendo lá de cima e a minha lanterna murchando o foco... Ai eu disse assim - ah filho da [palavra obscena], tu quer fazer medo, vai fazer medo para o [palavra obscena] da tua mãe... Mas antes eu nem tivesse mexido... veio aquele negócio de lá, parecia uma pedra assim... tu é doido! Fiquei doidinho... que vale que eu não perdi o rumo da estrada...Vim embora quando vi aquilo quente escorrendo na minha cara... Rezei o terço da espada e me empurrei... quando cheguei no campo, eu foquei a lanterna, eu olhei pra camisa chega tava vermelho isso aqui [o colarinho] de sangue... Tinha quebrado a minha cabeça... Não era pra eu ter mexido...era pra mim ter passado na minha viagem.. Ai eu aprendi... eu posso ver qualquer misura... já vi muita misura assim, mas ai eu não mexo mais... S. L, 49 anos.
\end{abstract}

Ficam evidenciados no trecho acima os dois aspectos que percebemos sobre as visagens: o respeito por elas e seus lugares, bem como a religiosidade necessária para afastá-las.

Já a Matinta Perera, que parece não se encaixar em nenhum dos três mundos que nos foi apresentado, é o motivo de maior temor das pessoas. Os moradores dizem que ela é uma feiticeira, mas que também é bicho, pois tem o poder de se "engerar", ou seja, de se transformar em um animal. Nas noites de lua, voa sobre as casas sendo seu assovio o aviso de que está se aproximando. $\mathrm{O}$ modo de descobrir quem é a matinta é oferecer tabaco ou café a ela durante o período que está engerada, pois na manhã seguinte, já em forma humana, é a primeira pessoa a aparecer na frente da casa de quem lhe fez a oferta cobrando o que fora prometido. A comunidade, de forma geral, afirma que a Matinta "é do mal". Ao contrário das outras criaturas que só "malinam" quando desrespeitadas, esta deve ser fortemente evitada, pois faz mal a quem passar próximo dela.

\footnotetext{
${ }^{2}$ É o nome localmente dado a uma árvore amazônica, muito alta, que dá o fruto conhecido como bacuri. A comunidade quilombola de Bairro Alto, assim como outras comunidades da Amazônia, o apreciam muito.
} 
Existem duas maneiras de se tornar Matinta, ou já se nasce com o fardo ou se é adquirido, depois de firmado um pacto com o Satanás. Os moradores contam que, a Matinta era uma mulher como outra qualquer, mas que, desejosa por conhecer os segredos e saberes do mundo, firma um pacto com o Satanás para ter acesso a todo esse conhecimento. Este por sua vez a presenteia com um livro, em que estão escritos todos os conhecimentos do mundo e que a fazem tornar-se feiticeira, no entanto, o preço pela realização de seu desejo é carregar o fardo de ser Matinta Perera pelo resto da vida.

Percebemos que esse ser representa grande receio para as pessoas, pela falta de conhecimento sobre a sua natureza. O receio, mas também, o medo, são os principais sentimentos humanos quando nos faltam informações acerca de alguma coisa. A natureza dual da Matinta, à primeira vista, causa exatamente esse sentimento nas pessoas que convivem com ela na comunidade, já que, por possuir uma habilidade transformacional conhecida e instável - apresentandose ora bicho ora gente - não se encaixaria em nenhum dos três mundos existentes no universo cosmológico local, que têm bem definidos os lugares dos humanos, dos encantados e dos espíritos. Se analisarmos a Matinta Perera sob a égide do que escreveu Viveiros de Castro (1996) sobre o perspectivismo ameríndio podemos fazer algumas observações, principalmente, em relação a sua teórica mudança de natureza.

O perspectivismo ameríndio parte do pressuposto de que haja uma unidade do espírito - aquilo que compõe o ser verdadeiramente, uma forma de intencionalidade ou subjetividade formalmente idêntica à consciência humana - e uma multiplicidade de corpos - que podem se apresentar de diferentes formas, sejam humanas ou não-humanas. Para Viveiros de Castro (1996) a diferença entre as subjetividades está nos pontos de vista, que são expressos por corporalidades diferentes, diferentes formas corporais. Ou seja, é o corpo que torna possível a mudança de pontos de vista, no entanto, a natureza do ser permanece a mesma.

No caso que apresentamos aqui, a Matinta Perera é o único ser, dentre os conhecidos pela comunidade de Bairro Alto, que possui reconhecidamente a habilidade transformacional e, portanto, uma teórica mudança de natureza. Os outros seres presentes na cosmologia local, que podem vir a apresentar o mesmo comportamento, não são reconhecidos pela população por apresentar tal habilidade, o que torna a Matinta Perera o ser que se diferencia de todos os outros e, por isso, causa de maior temor.

A natureza conflitante desse ser, que é frequentemente relatada pelos moradores, reside na verdade, no conhecimento de suas transformações corporais ou de acordo com Viveiros de Castro (1996), em suas mudanças de pontos de vista, que seria um fato amplamente conhecido pela população local. Enquanto os outros seres mudam de "roupa", ou seja, trocam sua corporalidade, sem o conhecimento de todos, a Matinta Perera não esconderia que sua verdadeira natureza reside no espírito e não no corpo, tornando essa troca amplamente sabida e, portanto, muito mais temida. 
A diversidade de mundos e de seres presentes na cosmologia local nos faz perceber que seu sistema de crenças modula as práticas locais estabelecidas com a natureza e com as outras pessoas e que a rede simbólica desenhada na região é muito mais complexa do que demonstra ser, se analisada apenas superficialmente. Práticas específicas, de grupos específicos também devem ser levadas em consideração para a compreensão dessa rede de significados. Sendo isso que nos deteremos a seguir.

\section{Os caçadores e seus amuletos}

Como compreendemos ao longo de todo o texto, a composição cosmológica da comunidade de Bairro Alto centra-se na existência de três mundos habitados por humanos e não humanos que se relacionam entre si e estabelecem formas de convívio. De forma geral, essas relações são universais e estendem-se por todos os indivíduos que compõem a comunidade, entretanto, existe uma tendência a se gerar práticas e crenças próprias em determinados grupos. Práticas essas que foram sendo desenvolvidas e perpetuadas com o passar das gerações, como é o caso dos caçadores.

Em pesquisa específica com os caçadores da comunidade, percebemos que $\mathrm{o}$ ato de caçar também envolve alguns elementos da cosmologia local. A utilização de amuletos como forma de afastar seres indesejados é bastante difundida e constantemente realizada pelas pessoas que exercem a atividade. Esses amuletos constituem-se, na maioria dos casos, da união de partes de animais e substâncias que são reconhecidamente eficazes para afastar o perigo como o sal grosso, o alho, a pimenta e o tabaco.

Dentre eles, o dente do jacaré-açu (Melanosuchus niger) (Figura 4) é indispensável aos caçadores que desejam se livrar das cobras, principalmente, a surucucu (Lachesis muta). É unânime entre todos os caçadores que, ao utilizar tal amuleto a cobra ou "não passa no caminho do caçador" ou "enterra sua cabeça no chão e não ataca”, pois o poder do jacaré-açu se sobrepõe ao dela. Carregar consigo um pouco de tabaco durante a andança no mato e fumar a "porronca", que é uma espécie de cachimbo onde se coloca o tabaco, também estão entre as maneiras de assegurar uma caçada sem maiores perigos e livres de visagens.

Ao analisarmos como esses amuletos surgem e se difundem no sistema de crenças dos quilombolas, é inevitável pensarmos em sua relação com o sobrenatural, com o mágico e dessa forma alinhar nossos pensamentos à teoria de Mauss (2003) quando escreve um ensaio sobre a Teoria Geral de Magia. O autor não chega a conceituar magia de forma definitiva, mas afirma que a magia compreende agentes, atos e representações (MAUSS, 2003:55), sendo, dessa forma, muito mais complexa do que se pensa. Com efeito, a prática de magia, segundo este autor, tem como finalidade reverter um estado de desagrado ou uma situação inaceitável. 


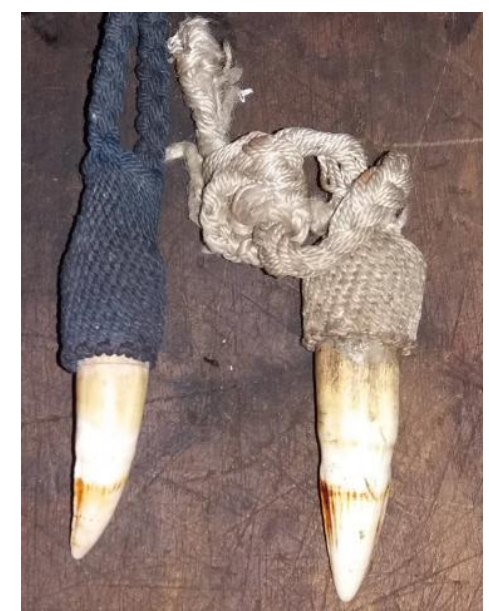

Figura 4: Amuleto de dente de jacaré-açu utilizado pelos caçadores. Foto: Maíra Melo. Outubro/2016.

Nesse sentido, o que primeiro devemos nos atentar é para as características que compõem a noção de ato mágico, a fim de estabelecermos conexões com as práticas observadas na comunidade de Bairro Alto. $\mathrm{O}$ autor afirma que o ato mágico possui três características importantes: a repetição, a crença coletiva e a eficácia garantida. Para ele, se uma determinada prática não alcança alguma dessas características não pode ser considerada mágica. Além disso, constrói a ideia de que atos mágicos são praticados às escondidas, em espaços secretos, permeados por segredos, em que o silêncio e o não compreendido são fundamentais para a eficácia da magia, pois a sua força está no não dito.

Mauss (2003) afirma ainda que as noções de magia e de religião se aproximam, e podem até ser confundidas, pois pertencem a mesma categoria: a do sagrado. Uma das distinções entre as duas que nos interessa, centra-se em suas naturezas opostas. Enquanto a religião tende a ser metafísica, a magia está mais ligada ao concreto. Se encaixarmos esses parâmetros nas práticas observadas na comunidade, percebemos que os atos mágicos, bem como a magia por ela mesma também medeiam as relações cosmológicas locais.

As práticas, de modo geral, respeitam a noção de ato mágico, pois são repetidas, não só pelos indivíduos como coletivamente, pelos grupos de caçadores, nos deixando concluir que são também práticas coletivas. E se essas práticas ganham tamanho alcance no tempo e no espaço é porque possuem eficácia, constituindo-se, então, como um ato mágico de acordo com a teoria proposta por Mauss. Além disso, não podemos esquecer que essas práticas possuem uma pitada de segredo, de silêncio. Conseguir que os caçadores falem a respeito de como se protegem em seu ofício, não é tarefa fácil, pois segundo os próprios, "não presta". Alguns comportamentos, como o ato de fumar a "porronca" e a utilização de amuletos, como o saco com tabaco no bolso, só puderam ser descritos a partir da observação das atividades de caça noturna. Nenhum de nossos interlocutores falou sobre o assunto, fato que encontra consonância com o que foi dito por Mauss. 
Ademais, as práticas dos caçadores, também mágicas, invadem o campo do sagrado ao exibirem em si tanto a religiosidade alcançada pelo metafísico, ao fazerem rezas, por exemplo, como também invadem o campo da magia alcançado pela concretização material. Esta ganha forma na presença dos amuletos, objetos reais, palpáveis, que são levados pelos caçadores em seu fazer natural.

\section{Considerações finais}

Ao adentrarmos na vida e no cotidiano da comunidade, percebemos que a cosmologia quilombola do Bairro Alto é fruto do cruzamento de culturas, pois guarda elementos oriundos tanto dos antepassados africanos como de povos indígenas. Contudo, ainda assim, podemos falar de uma natureza-cultura específica, uma vez que as histórias, as narrativas e as explicações dos mundos ganham corpo e características próprias do grupo social. Ademais, podemos concluir que a construção cosmológica modula as práticas cotidianas dos sujeitos, interferindo, mesmo que de forma indireta, em como utilizar e se apropriar do território, seja na caça, seja na pesca. Por fim, mencionamos que essa cosmologia constitui um dos pilares que sustenta a identidade quilombola, apontando para a necessidade da continuação de seus territórios, fundamentais à sua reprodução material e simbólica.

\section{Bibliografia}

ALBUQUERQUE, M. B. B; FARO, M. C. S. "Saberes de cura: um estudo sobre a pajelança cabocla e mulheres pajés da Amazônia". Revista Brasileira de História das Religiões, vol.5, n. 13, 2012, p. 57- 72.

BRASIL. Plano de Desenvolvimento Territorial Sustentável do Arquipélago do Marajó. Presidência da República. Casa Civil. Grupo Executivo Interministerial. Grupo executivo do Estado do Pará. 2007. 296p.

CLIFFORD, James. A Experiência Etnográfica. Rio de Janeiro: EdUFRJ, 1998.

DESCOLA, Philippe. "Las cosmologías indígenas de la Amazonia". In: SURRALLÉS, A; HIERRO, P. G. (Ed). Tierra adentro - Territorio indígena y percepción del entorno. Lima, Perú: Tarea Gráfica Educativa, 2004, p. 25 - 36.

ERIKSON, P. “'I”, "UUU”, "SHHH”: gritos, sexos e metamorfoses entre os Matis (Amazônia brasileira)”. Mana, vol. 6, n.2, 2000, p. 37-64.

FCP - Fundação Cultural Palmares. Disponível em: <www.palmares.gov.br> Acesso em 10 de março de 2016.

GARCIA, Uirá. Karawara - a caça e o mundo dos Awá-Guajá. Tese de doutorado, Antropologia. USP, 2010. 
. "KA'Á WATÁ, “Andar na Floresta”: Caça e território em um grupo Tupi da Amazônia”. Mediações, vol. 17, n.1, 2012a, p.172 - 190.

"O funeral do caçador: caça e perigo na Amazônia”. Anuário Antropológico [online], vol. II, 2012b, p. 33 - 55 .

HARRIS, M. “Traços de ser: Panema, santos e natureza na Amazônia”. In: Cultura e Etnicidade. Belém, UFPA: Humânitas, 2004. p. 57-82. Apud ALBUQUERQUE, M. B. B; FARO, M. C; S. "Saberes de cura: um estudo sobre a pajelança cabocla e mulheres pajés da Amazônia”. Revista Brasileira de História das Religiões, vol.5, n. 13, p. 57 - 72, 2012.

LATOUR, Bruno. Jamais fomos modernos. Rio de Janeiro, Editora 43, 1994.

LÉVI-STRAUS, Claude. O pensamento Selvagem. São Paulo, Ed. Papirus, 2005.

LEÃO, D. "Cosmologias da encantaria no Marajó-PA - Os encantados entre o rio e a configuração portuária da cidade de breves”. In: REA/ABANNE, Maceió, 5, 14,2015 .

LIMA, E. “Cobras, Xamãs e caçadores entre os katukina”. Tellus, vol. 8, n.15, 2008, p.35-57.

MALINOWSKI, Bronislaw. Os argonautas do pacífico ocidental. Ed. Abril Cultural, 1976.

MALUNGU. Coordenação estadual das associações de remanescentes de quilombos do Estado do Pará - MALUNGU. "Projeto nova cartografia social da Amazônia". Séries: Movimentos sociais, identidade coletiva e conflitos. Fascículo 7-Quilombolas da ilha do Marajó. 2006.

MAUÉS, Raymundo Heraldo. A Ilha Encantada: medicina e xamanismo numa comunidade de pescadores. Belém: UFPA, 1990.

- Padres, pajés, santos e festas: catolicismo popular e controle eclesiástico. Belém, CEJUP, 1995.

- Uma Outra "Invenção" da Amazônia: religiões, histórias, identidades. Belém: CEJUP, 1999.

"Um aspecto da diversidade cultural do caboclo amazônico: a religião”. Estudos avançados, vol.19, n. 53, 2005, p. 259 - 274.

MAUSS, Marcel. Sociologia e antropologia. São Paulo: Cosac Naify, 2003.

MAZZA, Fabiana. Cosmografia de um mundo perigoso - espaço e relações de afinidade entre os Jarawara da Amazônia. Tese de Doutorado, Antropologia, USP, 2009.

MDA/SIT. 2009. Caracterização do Município do Marajó - PA. Território Marajó. 
"http://sit.mda.gov.br/download.php?ac=obterDadosBas\&m=1501808"\&HYPE RLINK

"http://sit.mda.gov.br/download.php?ac=obterDadosBas\&m=1501808"m=150 1808> Acesso em 26 de Fev. de 2016.

POSEY, D.; ELISABETSKY, E. "Conceito de animais e seus espíritos em relação a doenças e curas entre os índios Kayapó da aldeia de Gorotire, Pará”. Boletim do Museu Paraense Emílio Goeldi. Série Antropologia, vol. 7, n. 1, 1991, p. 21 36.

SILVA, S. "Dualismo e cosmologia Kaingang: o xamã e o domínio da floresta”. Horizontes Antropológicos, vol. 8, n.18, 2002, p. 189 - 209.

STOLZE-LIMA, T. "O dois e seu múltiplo: Reflexões sobre o perspectivismo em uma cosmologia Tupi”. Mana, vol.2, n. 2, 1996, 21 - 47.

TEIXEIRA, R. "Todo lugar tem uma mãe: Sobre os filhos do Erepecuru”. Revista Anthropológicas, vol. 17, n.2, 2006, p. 117-146.

VEIGA, Juracilda. Cosmologia e práticas rituais Kaingang. Tese de doutorado, Antropologia, UNICAMP, 2000.

VIVEIROS DE CASTRO, Eduardo. Araweté - os deuses canibais. Rio de Janeiro: Jorge Zahar Ed, 1986.

- "Os Pronomes cosmológicos e o perspectivismo ameríndio". Mana, vol.2, n.2, 1996, p.115 - 144 .

"A floresta de cristal: notas sobre a ontologia dos espíritos amazônicos”. Cadernos de campo, São Paulo, n. 14/15, 2006, p.319 - 338.

WAWZYNIAK, J. "Humanos e não humanos no universo transformacional dos ribeirinhos do rio Tapajós-Pará”. Mediações - Revista de Ciências Sociais, v. 17, n.1, 2012, p. 17-32.

Assombro de olhada de bicho: uma etnografia das concepções e ações em saúde entre ribeirinhos do baixo rio Tapajós, Pará - Brasil. Tese Doutorado. Universidade Federal de São Carlos, São Carlos. 2008.

.“"Engerar”: uma categoria cosmológica sobre pessoa, saúde e corpo”.

Ilha: Revista de Antropologia, v. 5, n. 2, 2003, p. 33-55.

\section{Recebido em 31/10/2016. Aprovado em 11/11/2016.}

